\title{
7. Exercises to practice play
}

\author{
EXERCISE: PUZZLES AND QUILTS
}

\section{AUTHORS: HEIDI NECK AND PATRICIA GREENE}

\section{Description}

This exercise is an interactive challenge designed to help raise student awareness of the difference between managerial and entrepreneurial thinking. It also is a strong illustration of how to gain a better understanding of the impact of increasing degrees of uncertainty on the entrepreneurial process. Given the unprecedented level of uncertainty in business and entrepreneurship, students must learn how to navigate effectively in an increasingly uncertain world.

The exercise consists of students starting in one room with the task of completing a jigsaw puzzle. Students are systematically moved to another room, where they are asked to create a quilt from a selection of fabric pieces. The debrief explores jigsaw puzzles as managerial thinking and quilt making as entrepreneurial thinking. There is an optional debrief that includes leadership.

\section{Usage Suggestions}

This exercise works for all audiences, undergraduate, graduate, or practitioner. Ideally the exercise should be done on day one of a general entrepreneurship course as a way to set up how entrepreneurs think and the difference between entrepreneurial and managerial thinking.

\section{Learning Objectives}

- Experience the difference between managerial and entrepreneurial thinking.

- Engage with conditions of uncertainty and ambiguity.

- Illustrate how entrepreneurs think. 


\section{Materials List}

- Jigsaw puzzles (one per group, 300 pieces).

- Fabric remnants (approximately six pieces per person).

- Two rooms (one with tables equal to number of groups and one empty).

\section{Pre-Work Required by Students}

None.

\section{Theoretical Foundations}

Neck, H.M. 2011. Cognitive ambidexterity: The underlying mental model of the entrepreneurial leader. In D. Greenberg, K. McKone-Sweet, and H.J. Wilson (eds.), The New Entrepreneurial Leader: Developing Leaders Who Will Shape Social and Economic Opportunities (pp.24-42). San Francisco: Berrett-Koehler.

Sarasvathy, S. 2008. Effectuation: Elements of Entrepreneurial Expertise. Cheltenham, UK and Northampton, MA, USA: Edward Elgar Publishing.

Schlesinger, L., and Kieffer, C. 2012. Just Start. Cambridge, MA: Harvard Business School Press.

\section{Time Plan (60-80 minutes)}

The exercise begins in a room with tables for each team. Students are asked to clear their table in preparation. The second room required is a large empty space. A table (fairly long) is placed in front of this room or space, and fabric pieces are piled on the table. The piles should be messy, with all the fabrics mixed up (not sorted by size, color, or any other dimension).

\section{Puzzle time}

Divide students into groups of five to seven and give them the following directions: "Your task is quite easy but you don't have a lot of time. Your goal is to put together the puzzle that is sitting on the table as fast as you possibly can. It's only 300 pieces! You can do it. Get started. You are being timed. Don't worry; there are no cameras in the room!"

\section{Random pull-out to quilting room}

$$
\text { 0:05-0:30 (25 minutes) }
$$

Pull students at random from the puzzle room, one at a time, asking for one volunteer from each group. The individual volunteered or selected from each group is taken to the empty room with the table of fabric. 
At the fabric table the first group is told: "Your new task is quite easy but you don't have a lot of time. You are now designated quilt leaders. Your goal is to construct a design for a quilt. Choose six pieces of fabric from the table - no more and no less. Select an area in the room and begin to construct a quilt. You may not come back to the table for more or different fabric. No sewing is required. Simply place your fabric on the ground as if you were going to sew patches of fabric together to create the quilt. The goal is to build the best quilt you possibly can. Others will join you a bit later. Have fun!"

Note: Each quilt leader should choose six pieces of fabric, and each will begin his or her own quilt in different areas of the room.

Subsequent "volunteers" are taken out of the puzzle rooms at two- to three-minute intervals and instructed to take six pieces of fabric and join any quilt in progress that interests them. "Your new task is quite easy but you don't have a lot of time. Join one of the groups in the room. You do not have to stay with the team members from your puzzle group. Your goal is to construct a design for a quilt. Choose six pieces of fabric from the table - no more and no less. Next, join a group to help them build the best quilt you can. You may not exchange fabric once you choose. No sewing is required. Simply place your fabric on the ground as if you were going to sew patches of fabric together to create the quilt. Have fun!"

When all individuals are out of the puzzle room and in the quilt room, allow two more minutes to complete the quilts.

\section{Debrief}

0:30-1:00 (30 minutes)

The debrief may take place inside the quilt room or back in the classroom depending on group size. If debriefing inside the quilt room, have each quilt leader describe how the design of the quilt emerged. If debriefing outside the quilt room, give students time to walk through the quilt room to study all of the quilt designs before leaving the room.

Begin with questions:

- How many preferred the puzzle? Why?

- How many preferred the quilt? Why?

Focus on quilts:

- Ask the leaders about how the design came to be.

- Ask team members why they joined one team versus another.

- How did it feel moving from puzzle to quilts?

- What type of thinking was required for each part of the exercise? 
Summary At this time, it's important to introduce the concepts of puzzle as managerial thinking and quilts as entrepreneurial thinking.

Puzzle as managerial thinking:

- The goal is well defined (the puzzle picture is typically on the outside of the box).

- Determine resources to achieve the goal (puzzle pieces).

- Create a plan (put pieces in piles by color, and start with the edges).

- Execute the plan (edges first).

- Measure progress along the way.

- Goal achieved - the puzzle looks just like the picture on the front of the box! Well done!

Quilt as entrepreneurial thinking:

- Entrepreneurs start with what they have rather than what they need (fabric pieces).

- When entrepreneurs are not sure what to do their only choice is to act (pick a group and get to work).

- The design of the quilt emerges over time because it's difficult to plan (the quilt keeps changing every time a new person enters the group and the environment and resources change).

- You never really know when it's quite finished.

- Creating something new requires iteration rather than linear problem solving.

\section{Optional leadership debrief} 1:00-1:20 (20 minutes)

- What is leadership? (Ask them to write down their definition.)

- How did you "see" leadership around you? (Call on several different quilt groups.)

- How did you "see" followership?

- Who were the assigned leaders?

- Did the rest of you know there were assigned leaders?

- Pick an assigned leader and ask that person to describe his or her experience.

- When and how do you decide whether to lead or follow?

- What is the difference between leadership, management, and entrepreneurship?

- What is entrepreneurial leadership? 


\section{Key Takeaways}

- Under conditions of extreme uncertainty the only choice is action.

- One form of thinking (entrepreneurial or managerial) is not necessarily better than the other, yet it is important to understand the environmental context. If the skills for completing a jigsaw puzzle (managerial thinking) are used to solve a complicated problem in an uncertain environment, students are likely to run into one roadblock after another. However, if students can get more comfortable with quilt making (entrepreneurial thinking), then they may be able to navigate the terrain of entrepreneurship with greater aptitude.

- Action trumps planning in uncertain environments.

\section{Teaching Tips}

It is preferable not to refer to the exercise as the "quilt exercise" prior to conducting the exercise, as it rather gives away the punch line. Pacing is very important. As soon as the quilt leaders have placed their fabric on the ground, volunteers should be pulled out of the puzzle room approximately every three minutes. Fast pace is much better than a slow pace.

\section{Attribution}

The exercise is adapted from Saras Sarasvathy's crazy quilt principle within her work on effectual entrepreneurship. 


\title{
EXERCISE: BUILDING THE CULTURE OF YOUR BUSINESS WITH THE SIMS
}

\author{
AUTHOR: PATRICIA GREENE
}

\section{Description}

By the time most enterprise founders start thinking about ensuring a healthy culture in their business, it is usually too late. The culture has already emerged and is not always the most conducive to the health of the founder and employees, or even the enterprise itself. The culture of the enterprise emerges from the mind, values, and practices of the founder(s) while the business is being created, a time when the founder generally places more priority on the creation of economic value than the creation of culture. This exercise is based on a combination of organization and entrepreneurship theory and uses an off-the-shelf computer game, The Sims: Open for Business ${ }^{\mathrm{TM}}$, to investigate the core values, assumptions, interpretations, and approaches that combine to define the culture of a new venture. The students are assigned to play the game for a minimum of two hours outside of class, with no introduction given around the concept of culture. The heart of the exercise is the in-class debrief (including viewing the game), which reveals the culture that was created, what it means for all stakeholders, and what actions could be taken to adjust that culture.

\section{Usage Suggestions}

This content of the exercise works for all audiences, undergraduate, graduate, executive, or practitioner. The delivery requires that the students have access to the game and are able to play it before the discussion. The exercise lends itself well to online courses, as the debrief and illustration can also be done online, preferably in a synchronous mode, although asynchronous will work too. The exercise works best when each student is able to $\log$ on to his or her game for the debrief. This exercise is positioned in the course when emphasis is on resources. Culture is presented as a resource that can either add to or detract from the value of the company.

\section{Learning Objectives}

- Use and explain the critical interdisciplinary definitions related to organizational culture and entrepreneurship.

- Describe the relationship between organizational culture, structure, and leadership. 
- Evaluate personal approaches to a professional worklife.

- Design and assess an emerging organizational culture.

- Critically evaluate the approaches to the intentional creation of organizational culture.

\section{Materials List}

Video game: The Sims and the expansion packet The Sims: Open for Business $^{\mathrm{TM}}$.

\section{Pre-Work Required by Students}

Play The Sims: Open for Business ${ }^{\mathrm{TM}}$ for a minimum of two hours.

Suggested assigned reading:

Schein, Edgar H. 2010. Organizational Culture and Leadership, Vol. 2, Chapters 1 and 11. Wiley.com.

\section{Theoretical Foundations}

Barney, J.B. 1986. Organizational culture: Can it be a source of sustainable competitive advantage? Academy of Management Review, 11, 656-65.

Brush, C.G., Greene, P.G., and Hart, M.M. 2001. From initial idea to unique advantage: The entrepreneurial challenge of constructing a resource base. Academy of Management Executive, 15(1), 64-78.

Cameron, K.S., and Quinn, R.R. 1999. Diagnosing and Changing Organizational Culture: Based on the Competing Values Framework, Chapters 2 and 3 only. Reading, MA: Addison-Wesley.

Schein, E. 1983. The role of the founder in the creation of organizational culture.

Stinchcombe, A.L. 1965. Social structure and organizations. In J.G. March (ed.), Handbook of Organizations (pp. 142-93). Chicago: Rand-McNally.

\section{Time Plan (90 minutes)}

This 90-minute exercise can be adapted to fit various time schedules, including an entire class. Prior to the exercise the students would have been told to play the game for two hours. No other instructions are given. In this way, playing the game provides a shared experience and serves as the live case for the discussion. 
Step 1 (Introduction)

0:00-0:10 (10 minutes)

Ask the students to open their laptops and log on to their games. Each game should open at the point at which the student left the game. The opening or warm-up questions should be about just playing the game:

- How many of you had played some version of The Sims before? Anyone played this particular expansion version?

- How was it? Did you enjoy it? If so, why? If not, why?

- Were there any particular challenges?

- Where there any particular surprises?

- How long did you actually play? (Probe for who played the longest and why.)

Step 2

0:10-0:40 (30 minutes)

Divide students into groups of five to six and give them the following directions: "Please select a scribe and a reporter to first capture the themes of your work and then be ready to report out to the full class on your work. First, individually, each write down the answer to this question: What is the culture of the business you created - and how can you tell? You have five minutes for this individual work. After five minutes, and I'll tell you when the time is up, we'll switch to working with your team.

1. First, each student please share with your group the business you created.

2. Second, as a group create your list of criteria that create an organizational culture.

3. Third, please describe the impact of how people will carry out work given the culture you have created.

Step 3 (First report out and discussion)

0:40-1:10 (30 minutes)

Start with the first table and have the reporter share their top two criteria, along with an explanation and illustration of each. Then ask each table to add two criteria to the ones already listed. If desired, you can take a hand count at the end to establish what was considered as most important, and so on. The board map should match the theoretical criteria of your choice. For the purposes of this teaching note the primary source is Schein (1983) and focuses on the basic underlying assumptions around which cultural paradigms form. Examples include:

- The organization's relationship to its environment: Is recycling important?

- The nature of reality and truth: How important is time? 
- The nature of human nature: how employees (insiders) are treated and how customers (outsiders) are treated.

- The nature of human activity: the physical design of the employee break room.

- The nature of human relationships: Is the focus on competition or cooperation?

Summary and close

$1: 10-1: 30$ (20 minutes)

Ask the students to again work individually and list the three things they would keep about their culture and the three things they would change, along with how they would implement that change. Lead the closing discussion in such a way that the students discover:

1. What types of cultural approaches are common across most businesses?

2. What is the role of fit between the founder, the company, and the environment in creating culture?

3. How does culture become a positive resource for your business?

\section{Key Takeaways}

- The importance of intentionally creating organizational culture during firm emergence.

- Organizational culture can be a positive or negative firm resource.

- Organizational culture needs to be a fit between the founder, the firm, and the environment.

\section{Teaching Tips}

The game generally has to be ordered online, so you need to allow students time to order and receive it. The ideal experience is for the classroom to have wireless internet access and for each student to have a laptop. However, if teaching students with no access to computers or ability to buy the game, the instructor can lead the class in playing the game as a group, with one computer and the screen projected on the wall. 


\section{EXERCISE: RAINMAKERS}

\section{AUTHOR: HEIDI NECK}

\section{Description}

How do you make rain inside a room? This is the opening question for a playful, kinesthetic exercise that can help students begin to think more creatively and collaborate as a group. In a round circle of 15 or more, participants work together to create the sound of light rain that then escalates to a powerful storm and back to light rain.

\section{Usage Suggestions}

This exercise works for all audiences, undergraduate, graduate, and executive. The exercise is best positioned at the start of a session or a class as a non-traditional opener.

\section{Learning Objectives}

- Break the ice and build energy in a classroom setting.

- Encourage students to think more creatively when problem-solving.

- Feel how movement can be an active component of the learning process.

\section{Materials List}

None.

\section{Pre-Work Required by Students}

None.

\section{Theoretical Foundations}

Gardner, H. 2011. Frames of Mind: The Theory of Multiple Intelligences. New York: Basic Books. 


\section{Time Plan (15 minutes)}

\section{Exercise}

0:00-0:08 (8 minutes)

The instructor should begin with the following challenge: "If we wanted to make it rain in this classroom right now, how could this be accomplished?" Students will offer the more obvious solutions such as: light a fire so the sprinkler system will go off; bring in a bucket of water and throw it up in the air; shake a closed bottle of carbonated water and then open it. Note that many of these solutions are individual based, and they are neither realistic nor innovative.

When there are no more ideas, ask the students to form a circle (shoulder to shoulder) in the room and announce the following: "We are going to make rain together as a group. Only do what the person to your right is doing and don't start until the person on your right starts." The "rain" is made during a series of seven rounds. The instructor begins each round, and then the person to the left will do exactly as the instructor does. The rounds flow into one another; there is never a break in the flow of making the rain.

- Round 1: rubbing hands together. The instructor begins by rubbing his or her hands together palm to palm. The person on the immediate left should immediately follow. Eventually the entire group will be rubbing their hands together. When hand rubbing reaches the person to the immediate right of the instructor, it's time for round 2.

- Round 2: snaps. While everyone is still rubbing their hands together the instructor then begins snapping his or her fingers of both hands. The person on the left should immediately follow. Eventually the entire group will move from rubbing hands to snapping fingers. When the snapping of fingers reaches the person to the immediate right of the instructor, it's time for round 3.

- Round 3: slapping hands on thighs. Repeat the format of the previous rounds. Transition to round 4 when thigh slapping reaches the person to the instructor's immediate right.

- Round 4: stomping feet while slapping hands on thighs. The storm is at its peak during this round. Repeat the format of previous rounds.

- Round 5: return to slapping hands on thighs. Repeat the format of the previous rounds.

- Round 6: snaps return, and the storm begins to subside. Repeat the format of the previous rounds.

- Round 7: rub hands together so the light rain returns, and then end. Repeat the format of the previous rounds. 
Congratulate the students for making rain and creating a storm and initiate a round of applause.

Debrief

The following questions are suggested for debriefing:

0:08-0:15 (7 minutes)

- When I asked the question about creating rain, why did your answers not consider "sound" or other ways to create rain?

- What does this mean for how you think about creating opportunities? Problem solving?

- What was your reaction when I asked you to get into a circle?

- How did you feel before, during, and after the exercise?

\section{Key Takeaways}

- Our frames of reference are the starting point for problem solving and creating, yet these frames are limiting.

- There is usually uncertainty associated with asking students to get into a circle, but through collaboration this uncertainty is diminished and something completely unexpected is created.

- Entrepreneurship requires action. Simply moving your body can have an immediate impact on emotions, motivation, and confidence to continue.

\section{Teaching Tips}

Here are a few tips to ensure a true rainmaking experience:

- Every round must flow into the next without stopping.

- The instructor sets the tone for each round because he or she is the first to go. For example, it's important to slap hands on thighs rather hard to get the sound needed. The same can be said for stomping.

- Students have a tendency to want to all start rubbing their hands together when the first person starts. It's important that each person waits to start (or change) until the person to his or her right starts or changes. The instructor may have to start, stop, and restart in the first round to make the point regarding who does what activity when.

The following YouTube video illustrates the power of the exercise: http:// www.youtube.com/watch?v=LKDGCgXtETc. 


\section{Attribution}

This exercise has been used by teachers of all levels, though it's not clear who created the exercise. See http://www.teampedia.net/wiki/index. php?title=Make_it_Rain. 


\section{EXERCISE: IMPROVISATION FOR CREATIVITY}

\section{AUTHOR: LAKSHMI BALACHANDRA}

\section{Description}

This series of three short improvisational exercises offers students the opportunity to identify personal limitations to idea generation and reflect on situations where creativity may have been stifled. Students will consider their personal abilities and reactions to their improvisational abilities, as well as approaches to incorporate improvisational thinking in entrepreneurial endeavors. The overall goal is to demonstrate how students can develop an entrepreneurial mindset through improvisation. Such exercises are routinely used for developing improvisational actors as well as for pre-show warm-ups for the actors. This methodology was created in the 1960s and remains the standard by which individuals learn to improvise. Improvisation is an important component of the entrepreneurship method because idea generation and the ability to incorporate relevant, timely information are critical skills for developing new ventures that will not only survive but thrive.

\section{Usage Suggestions}

These exercises work for all audiences, undergraduate, graduate, or practitioner. It is particularly relevant for new venture creation courses, entrepreneurial creativity and/or leadership courses, entrepreneurship bootcamps, and workshops.

\section{Learning Objectives}

- Cultivate an entrepreneurial mindset.

- Recognize limitations of entrepreneurial thinking (what holds one back).

- Practice improvisation for idea generation and creativity.

\section{Materials List}

None. 


\section{Pre-Work Required by Students}

The optional readings below may be used for pre-work or post-work, depending on the audience.

\section{Theoretical Foundations}

Spolin, V. 1959. Improvisation for the Theater: A Handbook of Teaching and Directing Techniques. Evanston, IL: Northwestern University Press.

Johnstone, K. 1999. Impro for Storytellers. New York: Routledge/Theatre Arts Books.

Hmieleski, K.M., and Corbett, A.C. 2008. The contrasting interaction effects of improvisational behavior with entrepreneurial self-efficacy on new venture performance and entrepreneur work satisfaction. Journal of Business Venturing, 23(4), 482-96.

Neck, H.M. 2010. Idea generation. In B. Bygrave and A. Zacharakis (eds.), Portable MBA in Entrepreneurship (pp. 27-52). Hoboken, NJ: Wiley.

Balachandra, L., and Wheeler, M. 2006. What negotiators can learn from improv comedy. Negotiation, 9, 1-3.

\section{Time Plan (1 hour)}

This exercise can be extended to longer sessions so that students can begin brainstorming entrepreneurial ventures. For the purposes of an initial introduction to improvisation, this teaching note has been written so that the exercise requires at least 60 minutes.

Introduction

0:00-0:05 (5 minutes)

Begin the exercise by introducing the concept of improvisation: Ask students generally if they know what improvisation means. Opening questions for the discussion can include:

- What does improvisation mean to you?

- Where have you seen improvisation?

- Has anyone performed improvisation? Seen it performed?

Overview

0:05-0:15 (10 minutes)

Explain how the students will learn the basics of improvisation and see how they could apply it to entrepreneurship, in particular idea generation and creating new ventures. The instructor can show examples of comedy improvisation performance (either live or through video clips from YouTube. Some good short examples include scenes from the ABC show Whose Line Is It Anyway? An example clip can be found at http:// www.youtube.com/watch?v=Qd8bvNW9_h4). After sharing an example, 
discuss how performing improvisation can be learned: there are lessons offered for comedy improvisation and improvisational acting performance in improv theaters worldwide. An established framework exists to learn how to improvise. For this class, improvisation equals thinking on your feet. They will now be "in" an improv classroom, and every improvisation theater class begins with warm-ups. In order to think on their feet, they have to get up on their feet.

\section{Warm-up 1}

0:15-0:20 (5 minutes)

- Tell them to begin walking around the classroom and to observe every single object in the room.

- Then tell them to point at objects as they walk past them.

- As they point at each object they are to say what it is out loud - only they cannot call it what it actually is. They are to label it something it is not. And they are to do it quickly. Provide a quick example by pointing to an object in the room like the board and then say out loud "dog," and then point at another object like the desk and call it "potato" or whatever comes to mind.

After one to two minutes of them walking and pointing and labeling out loud, ask them to stop and be silent wherever they are for a group discussion.

When they stop, have them discuss how the experience of labeling objects was for them. Try to push them to explain what they were feeling. Some of the following questions can be used for this debrief:

- How was this experience?

- Did you find this exercise difficult to do? Why?

Summary of warm-up 1 Students should experience and be able to articulate:

- how difficult it is to break away from known "answers";

- how frequently they can get stuck in known patterns of thinking;

- the ease with which they start creating patterns with a known grouping (e.g. eggplant, cucumber, tomato, lettuce), which is a way to make the experience easier (get the "right" answer) as opposed to pushing and fostering creativity;

- the need for students to want to be in control, rather than searching for newness or playing;

- feeling the sense of awkwardness in saying the "wrong" label out 
loud, but having others around doing a similar activity makes the exercise less awkward;

- how easy it can be just to listen to others and follow their answers rather than coming up with their own new idea.

\section{Warm-up 2}

$0: 20-0: 25$ (5 minutes)

- Tell them to begin walking around the classroom again.

- When they come up to another student, they are to point at another student and name an animal, any animal that comes to mind, e.g. two students face each other and one points at the other and says "horse."

- Then tell them that the student who has been pointed at and labeled with a type of animal has to make the sound of the animal. If they do not know what sound the animal makes, they are to make it up and make some sort of sound.

- Then they switch, and the student who just produced the animal sound - in this example, the horse sounds - points at the first student and names an animal, e.g. "cat." This student then makes the sounds of whatever animal he or she was given.

- Once the interaction is completed, and both students in the pair have completed their animal sounds, they are to find new partners and repeat the warm-up exercise with two or three other students.

After two to three minutes of animal sounds, ask them to stop and be silent wherever they are for a group discussion.

Have them discuss how the experience of making animal sounds was for them. Try to push them again to explain what they were feeling. Some of the following questions can be used for this debrief:

- How was this experience?

- Did you find this exercise difficult to do? Why?

Summary of warm-up 2 Students should experience and be able to articulate:

- feeling a great sense of awkwardness - they are doing something they would normally be comfortable doing with children, but typically have never done in a classroom of adults or peers;

- not knowing the right "answer" or sound a particular animal makes, they would feel very frustrated, and then forget the instruction they were given to just make it up; 
- once again, the ease with which they follow patterns - patterns offer a way to make the exercise "easier," as they offer a means to come up with an answer or a label quickly rather than pushing creativity;

- how difficult it is for them to have no control as to what they have to do, rather than stepping back, enjoying the ambiguity, and searching for newness or playing;

- the fear they have of being "foolish" in a professional setting, how they do not want to be embarrassed by acting silly in front of others, and, in addition, the fear of feeling guilty, foolish, or rude for labeling others as certain types of animals with distinct connotations;

- this fear leads to self-judging and/or editing before they label their peer with an animal or before making the corresponding animal sound.

Warm-up 3

0:25-0:35 (10 minutes)

- Tell them to form groups of four wherever they are in the room.

- Then instruct them to play a game of word association, where anyone can go first, say a word, whatever word comes to mind.

- The person to the left listens to the word and then says a word that comes to mind based on the word he or she just heard.

- They continue in this way until you stop them, and they are to go as fast as they can (tell them to listen for further instruction).

- Once they get started, let them go for a minute or so, and then very loudly instruct them to "Switch directions!"

After another one to two minutes of word association, ask them to stop and be silent. You can have them return to their seats at this point or have them stay where they are for the final group discussion.

Now have them discuss how the word association experience was for them. Most will say this was easier to do, as they were in a group setting. So push them to explain what was happening rather than what they were feeling. Some of the following questions can be used for this debrief:

- How was this experience? If this was easier than the last two warmups, why?

- If you found this exercise more difficult than the last two, why?

- What happened when you were told to change directions? Why did this happen? 
Summary of warm-up 3 Students should experience and be able to articulate:

- the ease again they experienced of getting into routines or patterns how much they wanted to "control" the situation and outcomes;

- how much they were trying to be clever, or funny, rather than just coming up with any word that came to mind and following the exercise;

- typically they do not enjoy the ambiguity and opportunity to play and explore newness;

- self-judging occurs again, they feel limited in the direction for the exercise, and what words they allow themselves to say owing to their need to feel included or pressure to continue established patterns rather than pushing creativity and undefined randomness;

- students typically are not listening to the last word they just heard, and instead they focus on the words that people two ahead of them in the exercise are saying, as this way they can plan their response (this is highlighted with the change directions instruction).

Discussion

0:35-1:00 (25 minutes)

Once the students return to their seats, have them form groups of three to four and discuss what might be preventing their idea generation efforts related to initial new venture concepts. They should explore what holds them back when considering what they might do. Have them discuss the specific difficulties they experienced personally during the improvisation exercises and how they might get past these limitations to develop a more entrepreneurial mindset. Have a member of each group report out one recommendation for fostering creativity through improvisation. A closing discussion should include how to incorporate improvisation in their idea generation practices.

\section{Key Takeaways}

- How to incorporate improvisation to develop an entrepreneurial mindset: being quick on your feet and adapting or reacting rather than planning and pre-judging.

- Identifying and recognizing personal limitations to entrepreneurial thinking (why students are held back from creativity in idea generation, what their personal pitfalls are).

- How to develop an entrepreneurial mindset by incorporating tenets of fast and free thinking through improvisation for idea generation and creativity. 


\section{Teaching Tips}

It is important to keep the warm-up exercises moving fast. It might be helpful to tell the students before they begin the exercises that they will feel really uncomfortable, but feeling uncomfortable is the point of the exercise. In the debrief discussions, some students will genuinely enjoy the exercises and will say they found nothing in them difficult. Asking for a show of hands of those who found the exercise difficult to do first is often a better way to begin the debrief, before asking about how they found the experience (in case the students who enjoyed the exercises stifle the discussion). In warm-up 3 it is very helpful to move around the room encouraging groups to speed up their words so that there are no long pauses. It is important for them to think quickly and see how to come up with new ideas rather than thinking or planning and judging their ideas before they see where the new ideas can take them.

\section{Attribution}

These exercises are based on foundational exercises used in improvisational training, widely taught in improvisational theater courses worldwide. 


\section{EXERCISE: MARSHMALLOW TOWER}

\section{AUTHOR: BRADLEY GEORGE}

\section{Description}

Groups of students compete to see who can build the tallest freestanding structure supporting a marshmallow on top out of 20 pieces of spaghetti, three feet of tape and three feet of string. This exercise is used to illustrate that under conditions of uncertainty, entrepreneurs rely on experimentation and iterative learning as a means to discover information about their environment. Students are often taught and are familiar with traditional methods of planning and analysis, which work well in stable environments where the future is likely to be similar to the present. In these cases the future is fairly well known and understood. While some uncertainty exists, it can be categorized as risk. However, if the future is unknowable, the only way to learn what may work is through experimentation. Typically many of the students spend a large portion of their time designing and planning the structure and only start to build it at the end to find out at the last moment that it cannot support the weight of the marshmallow, and they then go into "crisis" mode. The teams that perform the best are usually those that just start experimenting, learning what works and then modifying their tower based on what they learn. If you are using lean start-up concepts it is also a good way to illustrate the value of market tests.

\section{Usage Suggestions}

This exercise works for all audiences, undergraduate, graduate, executive, or practitioner. It is appropriate for new venture creation courses, entrepreneurship bootcamps, or workshops. The session is best positioned early in the course for discussions around planning versus action.

\section{Learning Objectives}

- Practice and learn the concepts of effectual versus causal logic.

- Illustrate when planning is appropriate versus action.

- Employ experimentation techniques. 


\section{Materials List}

- Create a kit for each team (about four people per team), with each kit containing 20 sticks of spaghetti, one yard of masking tape, one yard of string, and one marshmallow. These ingredients should be placed into a paper lunch bag or manila envelope (excluding the masking tape), which simplifies distribution and hides the contents, maximizing the element of surprise. The masking tape should be hung on the desks or on the wall for distribution, as putting it in the bags generally causes problems.

- Ensure that you use uncooked spaghetti. Avoid spaghettini, as it is too thin and breaks easily. Fettuccine is too thick.

- Include string that can be easily broken by hand. If the string is thick, include scissors in your kit.

- Use standard-size marshmallows that measure about 1.5 inches across. Avoid mini or jumbo marshmallows. Also avoid stale marshmallows you want squishy marshmallows that give the impression of lightness.

- You will also need a measuring tape and a stopwatch or countdown application.

- Having a countdown application projected on the screen where they can see the time counting down is preferred (use an online stopwatch on your computer if convenient).

\section{Pre-Work Required by Students}

None.

\section{Theoretical Foundations}

Kiefer, C.F., and Schlesinger, L.A. 2010. Action Trumps Everything: Creating What You Want in an Uncertain World. Duxbury, MA: Black Ink Press.

Ries, E. 2011. The Lean Startup: How Today's Entrepreneurs Use Continuous Innovation to Create Radically Successful Businesses. New York: Crown Business.

Sarasvathy, S.D. 2001. Causation and effectuation: Towards a theoretical shift from economic inevitability to entrepreneurial contingency. Academy of Management Review, 26(2), 243-88.

\section{Time Plan (45 minutes)}

Step 1

0:00-0:05 (5 minutes)

Hand out the kits to each of the teams. Introduce the challenge. Be clear about the goals and rules of the Marshmallow Challenge. It is 
also helpful to tell them that this has been done by tens of thousands of people around the world from children to CEOs. The rules and goals are as follows.

Goal Build the tallest freestanding structure: The winning team is the one that has the tallest structure measured from the table top surface to the top of the marshmallow. That means the structure cannot be suspended from a higher structure, like a chair, ceiling, or chandelier.

\section{Rules}

- The entire marshmallow must be on top: The entire marshmallow needs to be on the top of the structure. Cutting or eating part of the marshmallow disqualifies the team.

- Use as much or as little of the kit as you choose: The team can use as many or as few of the 20 spaghetti sticks, and as much or as little of the string or tape, as they choose. The team cannot use the paper bag as part of their structure.

- Break up the spaghetti, string, or tape if you choose: Teams are free to break the spaghetti or cut up the tape and string to create new structures.

- The challenge lasts 18 minutes: Teams cannot hold on to the structure when the time runs out. Those touching or supporting the structure at the end of the exercise will be disqualified.

Ensure everyone understands the rules: Don't worry about repeating the rules too many times. Repeat them at least three times. Ask if anyone has any questions before starting; a good idea is to provide a handout with the instructions in the kit.

\section{Step 2}

0:05-0:25 (20 minutes)

Begin the challenge by starting the clock.

- Walk around the room and note the process that different teams are using.

- Remind the teams of the time: Increase the reminders as time gets shorter (for example, you might remind them at 9 minutes, 5 minutes, 3 minutes, 2 minutes, 1 minute, 30 seconds and then a 10 second countdown.

- Call out how the teams are doing: Let the entire group know how teams are progressing. Build a friendly rivalry and encourage people to look around. 
- Remind the teams that holders will be disqualified: Several teams will have the powerful desire to hold on to their structure at the end, usually because the marshmallow, which they just placed on to their structure moments before, is causing the structure to buckle. The winning structure needs to be stable.

Step 3

0:25-0:30 (5 minutes)

After the clock runs out, ask everyone in the room to sit down so everyone can see the structures. Usually only about half the teams will have a standing structure.

- Measure the structures: From the shortest standing structure to the tallest, measure and call out the heights. If you're documenting the challenge, have someone record the heights.

- Identify the winning team: Ensure they get a standing ovation and a prize (if you've offered one).

Step 4

$0: 30-0: 45$ (15 minutes)

Start by asking some of the teams about the process they used to go about building their structures. You can choose based on what you observed during the challenge. You will generally notice as you go around the room that teams that spend most of their time planning will fail to have a standing structure in the end. Those who experiment and learn through trial and error tend to do much better. It is usually best to start with some of the teams whose structures collapsed.

- What process did you use in building your structure?

- Focus on whether they spent a lot of time planning and drawing their structure or trial and error.

- What went wrong?

- This often highlights issues around unknown factors such as how much weight the spaghetti could support or how much the marshmallow weighed relative to the structure.

- How did you deal with that?

- This will often point out the fact that extensive planning leaves little time for adjusting and learning from experience and results in a "crisis."

Repeat this with one or more of the more successful groups and try to capture differences and commonalities between them.

You can draw comparisons to various other groups who have done this challenge. The creator of the challenge, Tom Wujec, has performed this 
challenge numerous times with a variety of different groups and has found the following:

- The best performers tend to be engineers (good thing). They understand structures and stresses, so this is a more certain environment for them.

- The worst performers tend to be recent business school graduates. They are in a very uncertain environment given limited knowledge about structures. However, they have typically been taught to plan, plan, plan. They spend most of their time planning and then try to build the structure at the last minute. When they put the marshmallow on top it weighs much more than they anticipated and the structure collapses, creating a crisis.

- After engineers, the best performers are recent kindergarten graduates. They are also in an uncertain environment, but they tend to experiment to see what works, learn from that, and build off it to create much more interesting structures.

Emphasize the importance of market tests and experimentation when entering a new, unknown environment. If your students are already working on business ideas, this can be a good place to have them try to think about low-cost ways they could experiment with their concept before making large investments.

As an alternative debrief, you can show the TED talk by the creator of this exercise by going to www.marshmallowchallenge.com.

\section{Key Takeaways}

- In an unknown environment, it is better to take action than to plan.

- Learning from small experiments and trials can produce more unique solutions - particularly if the future cannot be predicted.

- Failure can provide important insights to improving products or services.

\section{Teaching Tips}

Be very clear about the goals and rules of the challenge. Generally, you'll want to repeat them three times and reinforce them visually. In almost every challenge, there is at least one team who will want to cheat or bend the rules in their favor. The clearer you are about the rules the better the results. 


\section{Attribution}

This exercise was originally developed by Tom Wujec for teaching collaborative design. His website containing the instructions, a TED talk about the exercise, and other supporting material can be found at http:// marshmallowchallenge.com. 


\section{EXERCISE: AIRPLANE CONTEST}

\section{AUTHOR: BRADLEY GEORGE}

\section{Description}

Rocket pitches or elevator pitches are often the first opportunity for an entrepreneur to convince potential investors that they have an idea that represents a profitable opportunity. These are often only one- to five-minute presentations, but they can have a significant impact on the entrepreneur's ability to attract investors as well as other potential stakeholders. This can be particularly true in the early stages of a venture before the entrepreneur has a viable product, and he or she has to quickly convince potential stakeholders of his or her vision and the potential of the idea. Entrepreneurs often think that their idea is the most important aspect of the pitch, but studies have shown that U.S. venture capitalists consider personal characteristics such as the entrepreneur's ability to articulate his or her venture to be critical in determining whether or not they will reject an entrepreneur's plan.

In this exercise, students design a paper airplane that must be capable of carrying a predetermined amount of currency in the form of coins. The airplanes will compete in two categories - time that the plane can stay aloft and the distance it can travel. However, students pitch their design to their classmates (the investors) in an effort to convince them their design is the best before the contest takes place. The exercise has worked well for illustrating the importance of a good pitch and helps students to better understand what constitutes a good pitch from an investor's perspective.

\section{Usage Suggestions}

This exercise works with both undergraduate and graduate students. It is appropriate for new venture creation courses, entrepreneurship bootcamps, or workshops. The session is best positioned after students have identified a venture concept, project, or family or corporate initiative to pursue and are preparing for an elevator speech or rocket pitch type presentation. Technology entrepreneurship or innovation classes are also appropriate.

\section{Learning Objectives}

- Practice pitching new concepts.

- Critique pitches for new concepts. 
- Understand the importance of pitch versus idea.

- Simulate prototype development and feasibility testing.

\section{Materials List}

Provide students with paper for their airplanes in order to maintain a standard paper type and weight. Alternatively, you can leave this open to interpretation as a means of encouraging greater creativity among the teams. You will need a tape measure and a stopwatch for the actual competition.

\section{Pre-Work Required by Students}

Students are to be given the following instructions in the class period prior to running the exercise: "You are to design and create a new paper airplane capable of keeping one U.S. dollar of coins aloft for as long (time) as possible while simultaneously transporting the coins as far (distance) as possible. The assignment is as follows:

1. You may work individually or in a group of up to four students; the only group-related implication is that your airplane design must use the same number of standard size sheets as the number of people in the group (for example, a group of four must create an airplane that uses four sheets of paper in its design).

2. Your plane must be designed to transport one U.S. dollar of coinage (or other local currency). You may choose the number and denominations of coins used; your only constraint is that their total value be exactly one dollar.

3. You may not simply crumple the paper into a ball, as this would constitute a projectile rather than an aerodynamically sensitive aircraftbased design.

You will be required to pitch your design to your classmates. You will have two minutes to convince your classmates that your design will perform the best. Performance on the exercise will be based on a combination of actual performance of your airplane and the number of votes your design gets from your classmates in each category (time and distance)." 


\section{Theoretical Foundations}

MacMillan, I.C., Siegel, R., and Subba Narisimha, P.N. 1985. Criteria used by venture capitalists to evaluate new venture proposals. Journal of Business Venturing, 1, 119-28.

Ries, E. 2011. The Lean Startup: How Today's Entrepreneurs Use Continuous Innovation to Create Radically Successful Businesses. New York: Crown Publishing.

\section{Time Plan (80 minutes)}

Because each team will pitch their idea, the time required for the exercise will vary with class and team size. The timing outlined here is based on a class size of 30 students and ten teams.

\section{Step 1}

0:00-0:02 (2 minutes)

Begin the exercise by explaining the voting rules to the students. Students are allowed to vote for only one team (excluding their own) in each of the two categories (distance and time). They are not required to vote for the same design in each category. It helps to provide a sheet for each of the students to record their votes, or, if your students have computers and internet access, you can use an online voting system (this will require you to set it up before the class).

\section{Step 2}

0:02-0:27 (25 minutes)

Next, have each team pitch their idea to their classmates. Teams should be strictly limited to two minutes each.

\section{Step 3}

0:27-0:32 (5 minutes)

Have the students record their votes for the design they think will perform best in each category. Remind them that they cannot vote for their own design.

\section{Step 4}

0:32-0:52 (20 minutes)

Take the class to an open area in which to conduct the actual flights. An indoor area such as a gymnasium works best, but you can run it outdoors as well (which can introduce additional uncertainty into the performance for the students).

Each team gets one throw. You should have a line that they cannot cross for throwing, and you should record the time that their plane stays aloft. After the plane has landed, measure and record the distance. It helps if you assign this task to one or more of the students. 
Step 5

0:52-1:00 (8 minutes)

Return to the classroom. Record the votes and the actual performance for each team on the board.

Step 6 (exercise debrief)

1:00-1:20 (20 minutes)

If time allows, you can have a short discussion about their process with regard to creating their design. This can help to illustrate how an entrepreneur can take a constraint and turn it into an opportunity. Additionally, this can highlight the importance of prototyping and learning from failure, and many of the teams that perform well often trial several different designs. Some possible questions include:

- How did they view the issue of the coins?

- Did they see it as a negative constraint? Why?

- Did they see it as an opportunity to incorporate it into the design and improve its performance?

- How did they try to differentiate their design?

- Did they try to optimize for time or distance or try both?

- Did they prototype and test designs?

Next, discuss the aspect of effective pitching. The idea here is to get them to appreciate the importance of the entrepreneur and his or her pitch to investors. Owing to the uncertainty inherent in many early-stage entrepreneurial ventures, investors will typically put more emphasis on the entrepreneur and his or her ability to "sell" the idea, as well as their confidence in the entrepreneur's ability to execute on his or her pitch - one has to be careful not to oversell the concept.

- How did it feel to try to "sell" your classmates on your design?

- What were the biggest challenges?

- How did you decide to invest?

- How important was the way in which they presented the concept?

- Confidence?

- What was compelling about the pitch or the entrepreneur?

- Why do you think people did or did not vote for your design?

- What would you do to improve your pitch?

Wrap the discussion up with a summary of the importance of clearly articulating your idea and convincing the audience of your ability to execute on your idea. 


\section{Post-Work}

Have the students read the following articles (this can be done beforehand if you prefer):

Elsbach, K.D. 2003. How to pitch a brilliant idea. Harvard Business Review, 81(9), $117-23$.

Santinelli, A., and Brush, C. 2013. Designing and Delivering the Perfect Pitch. Wellesley, MA: Babson College Case Collection.

\section{Teaching Tips}

Students will often try to game the system (depending on how much freedom you give them). For example, they may choose to use different weights of paper or design a flying disc as opposed to a traditional airplane. You can decide how vague you want to be. If you want to have more discussion on the creative process and pushing the boundaries, then being more vague in the instructions can lead to a good discussion on how entrepreneurs try to push the rules and boundaries. Some students will feel "cheated," but this can still provide a good learning point.

\section{Key Takeaways}

- Ability to quickly and clearly articulate an idea is often more important than the idea itself.

- Investors often focus on their belief in the entrepreneur's ability to execute on the idea rather than the idea itself - particularly under conditions of uncertainty.

- Prototyping can be an effective way to deal with an unknown environment and develop your product or service.

\section{Attribution}

Reginald A. Litz, Dell McStay, Sergio Janczak, and Carolyn Birmingham, "Kitty hawk in the classroom: A simulation exercise for facilitating creative and entrepreneurial behavior," United States Association for Small Business and Entrepreneurship (USASBE) 2011 conference Entrepreneurship: Changing the Present, Creating the Future, South Carolina, United States, January 2011. 


\section{EXERCISE: BUSINESS MODEL CANVAS GAME}

\section{AUTHOR: HEIDI NECK}

\section{Description}

The Business Model Canvas (http://www.businessmodelgeneration.com/ canvas) has become a popular teaching tool in entrepreneurship classrooms. It is not my intention here to introduce the canvas or illustrate how it works. Osterwalder and Pigneur (2010) do a magnificent job explaining the canvas, articulating the theory behind the canvas, and offering many ways to use the canvas. This exercise is a quick game to help students reflect on the nature and ordering of the nine business model components found on the canvas as proposed by Osterwalder and Pigneur.

\section{Usage Suggestions}

This exercise works well for both undergraduate and graduate audiences. The exercise is best used in a course or class session where the Business Model Canvas is first being introduced.

\section{Learning Objectives}

- Reflect on the meaning and importance of the nine business model components.

- Demonstrate how the ordering on the canvas categorizes components as generating value or creating efficiency to deliver value.

- Discuss and debate the ordering proposed by Osterwalder and Pigneur (2010).

\section{Materials List}

Instructors will need to create decks of "business model component cards." One deck is needed per team in the class. Each deck is comprised of nine index cards. On each card should be one of the nine business model components: customer segments, value propositions, channels, customer relationships, revenue streams, key resources, key activities, key partners, cost structure. Given that this is the actual order recommended by Osterwalder \& Pigneur, it is important that the cards in the deck are not in this order. You may also want to have copies of the Business Model Canvas to distribute as well, but after the game. A copy of the canvas can be obtained at http://www.businessmodelgeneration.com/canvas. 


\section{Pre-Work Required by Students}

None.

\section{Theoretical Foundations}

Osterwalder, A., and Pigneur, Y. 2010. Business Model Generation. Hoboken, NJ: John Wiley \& Sons.

\section{Time Plan (30 minutes)}

The Game Setup

0:00-0:05 (5 minutes) Before introducing the canvas, simply introduce that there are nine components of a business model. I typically show a PowerPoint slide with the nine components listed in random order. Tell the students that there is a particular order to the components, but they need to figure out what the order is. In other words, they need to determine which of the components should be considered first, second, and so on. What's most important to start with and what's least important? Separate students into teams of five (maximum).

The Game

0:05-0:15 (10 minutes)

Give each team a deck of cards and ask them to place them in order from one to nine (10 minutes). After 10 minutes, give each team a long piece of masking tape and have them tape the order of their cards to the wall or board, so everyone can see the differences across the team.

\section{The Discussion}

0:15-0:30 (15 minutes)

Now it is time to introduce the ordering that Osterwalder and Pigneur use. Their book (see Theoretical Foundations) is quite helpful if you are not familiar with the canvas. I typically give out a copy of the Business Model Canvas to each student prior to disclosing the order.

The ordering of the components is: 1) customer segments, 2) value propositions, 3) channels, 4) customer relationships, 5) revenue streams, 6) key resources, 7) key activities, 8) key partners, 9) cost structure. Usually student teams will have either customer segments or value propositions first and this creates a wonderful debate in the class. Introduce the order of the components one by one while also explaining what each component is.

After walking through the components and discussing the differences in order created by each team I end the exercise with a brief discussion summarizing the order. At the end of the day, the ordering really does not matter because the canvas is meant to be an iterative, working document 
that will continuously change as you learn new information from every action taken or experiment conducted. What is most interesting about the design of the canvas and its ordering is found when you fold the canvas in half (left to right). According to Osterwalder and Pigneur, the right side of the canvas is concerned with creating and generating value. The left side of the canvas is concerned with generating efficiencies to deliver that value. As such, an entrepreneur needs to first determine or create the value and then develop the approach to deliver that value. Innovation, novelty, creativity, and competitive advantage are most often found in the value creation. So, start on the right!

\section{Key Takeaways}

- It is important to think about the ordering of the components but not be wedded to one particular ordering.

- A business model is about value creation, delivery, and capture - but start with creation and think about cost last.

- Focusing too soon on cost structure and resources can diminish the innovativeness of new ideas. This can happen when we start on the left side of the canvas.

\section{Teaching Tips}

The most important reason that I do this exercise is to get the students thinking about each component on their own in teams rather than just "telling" them about each component. Expect raging debates about customer segments versus value propositions as being first in the order. It is always a great conversation to have. 